BMJ Open

Sport \&

Exercise

Medicine

\title{
Exertional rhabdomyolysis: physiological response or manifestation of an underlying myopathy?
}

\author{
Renata S Scalco, ${ }^{1}$ Marc Snoeck, ${ }^{2}$ Ros Quinlivan, ${ }^{1}$ Susan Treves, ${ }^{3,4}$ \\ Pascal Laforét, ${ }^{5}$ Heinz Jungbluth, ${ }^{6,7,8}$ Nicol C Voermans ${ }^{9}$
}

To cite: Scalco RS,

Snoeck M, Quinlivan R, et al. Exertional rhabdomyolysis: physiological response or manifestation of an underlying myopathy? BMJ Open Sport Exerc Med 2016;2:e000151.

doi:10.1136/bmjsem-2016000151

- Prepublication history for this paper is available online To view these files please visit the journal online (http://dx.doi.org/10.1136/ bmjsem-2016-000151).

HJ and NCV shared senior authorship.

Accepted 1 August 2016

CrossMark

For numbered affiliations see end of article.

Correspondence to Dr Renata Scalco; r.scalco@ ucl.ac.uk

\section{ABSTRACT}

Exertional rhabdomyolysis is characterised by muscle breakdown associated with strenuous exercise or normal exercise under extreme circumstances. Key features are severe muscle pain and sudden transient elevation of serum creatine kinase (CK) levels with or without associated myoglobinuria. Mild cases may remain unnoticed or undiagnosed. Exertional rhabdomyolysis is well described among athletes and military personnel, but may occur in anybody exposed to unaccustomed exercise. In contrast, exertional rhabdomyolysis may be the first manifestation of a genetic muscle disease that lowers the exercise threshold for developing muscle breakdown. Repeated episodes of exertional rhabdomyolysis should raise the suspicion of such an underlying disorder, in particular in individuals in whom the severity of the rhabdomyolysis episodes exceeds the expected response to the exercise performed. The present review aims to provide a practical guideline for the acute management and postepisode counselling of patients with exertional rhabdomyolysis, with a particular emphasis on when to suspect an underlying genetic disorder. The pathophysiology and its clinical features are reviewed, emphasising four main stepwise approaches: (1) the clinical significance of an acute episode, (2) risks of renal impairment, (3) clinical indicators of an underlying genetic disorders and (4) when and how to recommence sport activity following an acute episode of rhabdomyolysis. Genetic backgrounds that appear to be associated with both enhanced athletic performance and increased rhabdomyolysis risk are briefly reviewed.

\section{INTRODUCTION}

Exertional rhabdomyolysis (ERM) is the general term for muscle breakdown associated with strenuous exercise and is well described among athletes and military personnel. Although there is no universally accepted definition, ERM is often defined as a clinical syndrome associated with severe muscle pain, sudden elevation (and subsequent fall) of serum creatine kinase (CK) levels with or without myoglobinuria. Individuals experiencing ERM present to a

\section{What are the new findings}

- Exertional rhabdomyolysis (ERM) may be the first manifestation of a genetic muscle disease that lowers the exercise threshold for developing muscle breakdown.

- Consider a genetic cause of the ERM in case of recurrent episodes; high creatine kinase (CK) levels ( $>50 \times$ upper limit of normal) or persisting hyperCKaemia; absence of unaccustomed exercise; absence of (recreational or medical) drugs; or a positive family history of rhabdomyolysis or other exertional symptoms.

- Type 1 ryanodine receptor (RYR1) mutations have been recently recognised to account for a substantial proportion of patients presenting with ERM.

- Participants with a genetic predisposition to ERM need specific guidance when they recommence exercise and sporting activities.

variety of physicians, in particular to general practitioners and physicians working in sports medicine, emergency and internal medicine, neurology and the neuromuscular field, and for the military. As a result of the diversity of medical personnel having to deal with ERM, most physicians will have experience with some but not necessarily all aspects of this important condition.

ERM results in the entry of skeletal muscle contents, in particular CK and myoglobin, into the systemic circulation. In most cases, the condition has a mild course characterised by postexertional myalgia with mild-to-moderate CK increases, mild pigmenturia, and will often not even come to medical attention. However, in a minority of patients the clinical course can be severe, resulting in marked hyperCKaemia, compartment syndrome, acute renal injury, disseminated intravascular coagulation, cardiac arrhythmias secondary to electrolyte imbalances, and even cardiac arrest if left untreated. The annual rhabdomyolysis 
prevalence has been reported as 26000 cases in the USA, with $47 \%$ meeting the diagnostic criteria of ERM. ${ }^{1}$ In other studies, a lower percentage of ERM has been suggested, ${ }^{2}$ a discrepancy which reflects differences in the cohorts studied.

ERM most often represents a 'physiological' response to extreme physical exercise or to normal exercise under extreme circumstances. In contrast, ERM might also be the first manifestation of a genetic muscle disease, which lowers the exercise threshold for developing muscle breakdown. A genetic cause should always be considered in individuals with repeated episodes of ERM and in those in whom the severity of rhabdomyolysis exceeds the expected response to the exercise performed.

The recognition of a patient with an underlying genetic disorder is essential for acute management as well as (and most importantly) for counselling afterwards. First, in type 1 ryanodine receptor (RYR1)-related cases of ERM, ${ }^{3}$ the specific RyR1 antagonist dantrolene could be administered to limit further muscle breakdown and CK increases and more severe, potentially lifethreatening downstream medical complications. Patients with RYR1-related ERM will have a higher recurrence risk and will have to be specifically advised with regard to subsequent sporting activities. The same patients are also at increased risk of malignant hyperthermia susceptibility (MHS), a pharmacogenetic response to volatile anaesthetics and/or the depolarising muscle relaxant succinylcholine, with important consequences for affected individuals but possibly also for their relatives carrying the same RYR1 variants. Furthermore, certain genetic myopathies carrying an increased rhabdomyolysis risk may also be associated with cardiac or other systemic symptoms that will have to be screened for. Finally, certain medications may be relatively contraindicated and exercise advice should be individually adapted in case of an underlying genetic cause.

The present review therefore aims to provide a practical guideline for the acute management and postepisode counselling of patients with ERM. The vast majority of the relevant literature until now has focused either on the physiological circumstances of ERM (particularly in publications with an emphasis on sports or military medicine), ${ }^{45}$ on general causes of rhabdomyolysis, ${ }^{6}$ or on genetic myopathies which may predispose to rhabdomyolysis (particularly in publications with an emphasis on emergency medicine, genetics, neurology and neuromuscular medicine). ${ }^{7-9}$ As a result, physicians working in sports or military and emergency medicine are well updated on the symptoms and management of ERM, but may find it difficult to decide when to consider an underlying genetic disorder. On the other hand, a neurologist may perform unnecessary muscle biopsies in healthy individuals who have suffered from a single episode of ERM after extreme unaccustomed exercise. Therefore, a combined approach is necessary to recognise individuals who are at risk for recurrent rhabdomyolysis and to advise patients with certain genetic disorders on when and how to recommence exercise and sporting activities.

We will first discuss the pathophysiology of ERM and its typical clinical features, and provide examples of typical physiological ERM. Next, we will propose a structured approach to patients with ERM, based on the following four key questions: (1) is the ERM clinically significant, requiring hospital admission and intravenous fluids administration? (2) What is the risk of developing acute renal failure (ARF)? (3) Is the ERM the (first) manifestation of a genetic disorder? And (4) when and how to restart exercise and sporting activities? We expect that such an approach will be of benefit for a wide range of physicians facing this severe and challenging condition in different medical settings.

\section{WHAT IS ERM? \\ Background}

In muscle tissue, the process of neuronal signal transduction leading to muscle contraction is called excitationcontraction coupling (ECC). During ECC, presynaptic acetylcholine release induces postsynaptic depolarisation of the sarcolemma, resulting in activation of the voltagegated L-type calcium channels (also known as dihydropyridine receptors (DHPRs)). Unlike in cardiac muscle, it is not this calcium influx itself but rather the direct interaction between DHPRs and RyR1s that causes the opening of RyR1 $\mathrm{Ca}^{2+}$ channels, leading to a rapid release of $\mathrm{Ca}^{2+}$ from the intracellular sarcoplasmic reticulum (SR) stores. The increased myoplasmic $\mathrm{Ca}^{2+}$ (from about $10^{-7}$ to $10^{-5} \mathrm{M}$ ) induces the effective interaction between thick and thin filaments by binding to troponin $\mathrm{C}$, and this ultimately leads to muscle contraction. After contraction, calcium needs to be restored. This happens through active transport facilitated by the $\mathrm{Ca}^{2+}$ ATPase, an active process that on the molecular level takes $10^{5}$ times longer than does RyR1-induced calcium release but is compensated for by the large number of $\mathrm{Ca}^{2}$ ${ }^{+}$-ATPases on the surface of the SR membrane. ${ }^{10}$

Irrespective of its cause(s), the pathophysiological events in rhabdomyolysis follow a common pathway. Normally, ion pumps and channels in the sarcolemma maintain a low intracellular $\mathrm{Na}^{+}$and $\mathrm{Ca}^{2+}$ and a high intracellular $\mathrm{K}^{+}$concentration. Unaccustomed exercise may cause direct injury to the sarcolemma (eg, in eccentric exercise) and/or lead to failure of energy production with subsequent pump dysfunction of $\mathrm{Na}^{+} / \mathrm{K}^{+}$ATPase and $\mathrm{Ca}^{2+}$ ATPase (eg, in prolonged training beyond the limit of fatigue). Both processes lead to increased cellular permeability to sodium ions and, consequently, increased intracellular calcium concentrations, with concordant muscle contraction increasing the energy deficit. This increased intracellular calcium concentration also enhances the activation of calciumdependent proteases and phospholipases, which contributes to destruction of myofibrillar, cytoskeletal and membrane proteins. Subsequently, large quantities of 
intracellular electrolytes, metabolites (potassium, phosphate and urate) as well as intracellular proteins (aldolase, myoglobin, CK, lactate dehydrogenase, aspartate transaminase) leak into the circulation. The resulting free calcium will only add to the contraction of the already overactivated surrounding myocytes, resulting in a vicious circle (figure 1 ).

Electrolyte disturbances occurring during exercise (hypokalaemia by perspiration; hyponatraemia due to polydipsia or medications) reinforce this process. Fluid sequestration by damaged muscle leads to profound intravascular volume depletion. This shift may over time exceed $15 \mathrm{~L}$ and exacerbates the potential for ARF. Potassium release from muscle cells during exercise normally mediates vasodilation and an appropriately increased blood flow to muscles. Decreased potassium release due to profound hypokalaemia (serum potassium $<2.5 \mathrm{mEq} / \mathrm{L}$ ) may promote the development of rhabdomyolysis by decreasing blood flow to muscles in response to exertion, thus limiting availability of energy sources. As rhabdomyolysis develops, potassium leaks from myocytes into the bloodstream causing hyperkalaemia, which can result in fatal cardiac arrhythmias. Hyponatraemia contributes to $\mathrm{Na}^{+} / \mathrm{Ca}^{2+}$-ATPase dysfunction, which leads to the activation of proteases and lipases that are responsible for further cell lysis. Furthermore, hyponatraemia causes failure of cell volume regulation, leading to exertional cell lysis that may stimulate vasopressin secretion. ${ }^{11}$ Thus, rhabdomyolysis may occur during the development of hyponatraemia, or during its correction. ${ }^{12}$ Combined with other cellular responses to exercise such as increased oxidative stress ${ }^{13}$ and release of proinflammatory cytokines, ${ }^{14}$ this will ultimately result in cell death and intracellular components spilling into the surrounding tissue.

Myoglobin, the haemprotein that functions as an oxygen carrier in skeletal muscle, is normally bound to plasma globulins. In case of rhabdomyolysis, myoglobin leaks from the myocyte and immediately peaks to levels that may exceed the plasma protein-binding capacity. As a result, myoglobin precipitates in the glomerular filtrate and obstructs renal tubules, an important factor in the pathogenesis of ARF. Other factors contributing to ARF include vasoconstriction, hypovolaemia and a direct renal toxic effect of myoglobin. ${ }^{15}$

In our experience, rhabdomyolysis mainly occurs in the muscles that are most frequently used. The type of exercise performed also plays an important role in ERM. In particular, eccentric training, for example, squats, lunges, push-ups, plyometrics or running downhill, carries a risk of causing ERM. Repetitive eccentric contractions, a process where the muscle is lengthening while trying to contract, cause excess tension in the sarcomere, leading to membrane disruption and, subsequently, structural protein hydrolysis, myofibril deformation and permanent muscle injury. Eccentric exercise has also been associated with core formation on muscle biopsy, usually a histopathological hallmark of congenital myopathies. ${ }^{16}$

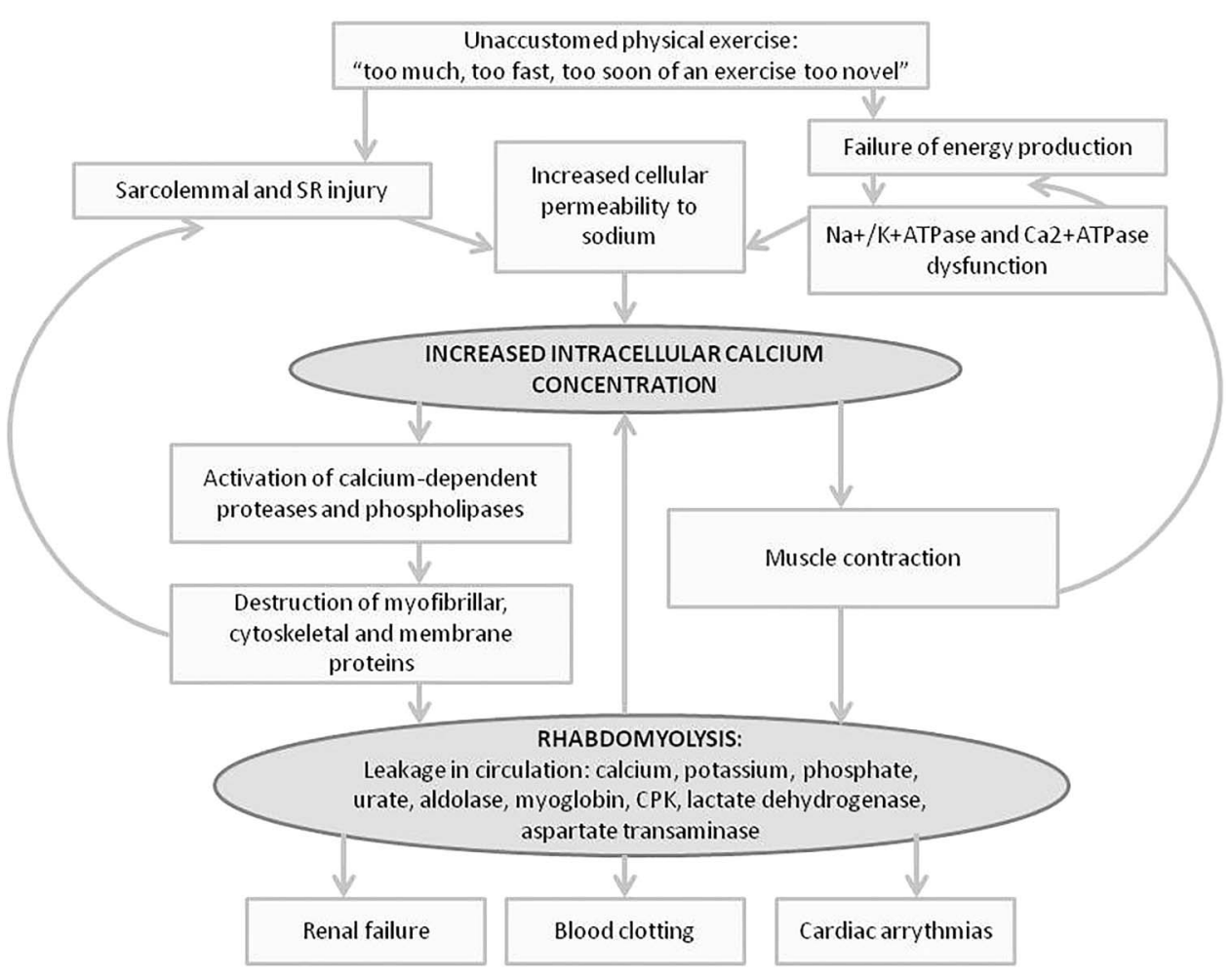

Figure 1 Pathophysiology of rhabdomyolysis. The pathophysiological events in rhabdomyolysis follow a common pathway, irrespective of its cause. CK, creatine kinase; SR, sarcoplasmic reticulum. 


\section{Definition of ERM}

What is generally agreed on are the following four key features of rhabdomyolysis:

1. A CK elevation 12-36 hours after exercise, with a maximum at 3-4 days, followed by normalisation within several weeks of rest;

2. The CK increase is preceded by exercise, usually beyond the limits of fatigue, also referred to as 'unaccustomed physical exertion' or 'involuntary exertion';

3. The CK increase is symptomatic with any of the following features: myalgia (muscle soreness or tenderness; in general, rhabdomyolysis is very painful), swelling and/or weakness;

4. The presence of myoglobinaemia and/or myoglobinuria: either by inspection (pigmenturia) or by laboratory testing. Since myoglobin testing in blood or urine is not widely available, many experts consider the combination of the first three features diagnostic for ERM.

\section{CK elevation}

The presence of elevated serum myoglobin was once used routinely to diagnose rhabdomyolysis; however, this parameter is not widely available for diagnostic testing and unreliable because myoglobin is rapidly cleared from the blood. Laboratory testing in urine (a positive dipstick for blood with absence of red blood cells on microscopic urinalysis serves as an indirect marker of urinary myoglobin) offers a fast screening tool if serum myoglobin testing is not readily available. Serum CK is the most reliable diagnostic marker of rhabdomyolysis. It usually peaks 24-36 hours after exertion and then decreases back to baseline at a rate of about $40 \%$ per day (figure 2). ${ }^{17}$

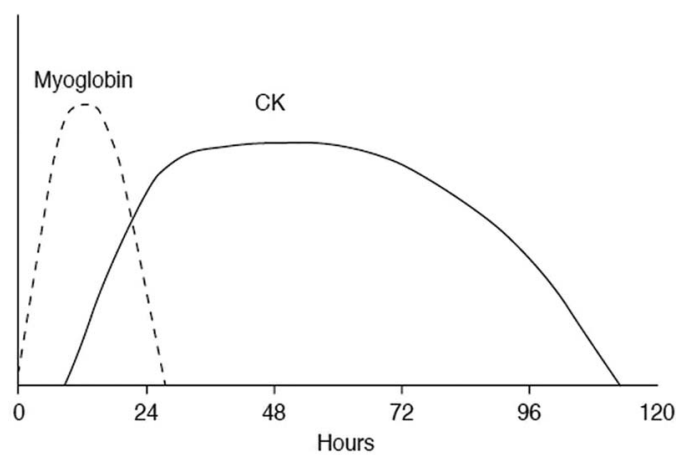

Figure 2 Rise and fall of myoglobin and creatine kinase (CK) during the course of rhabdomyolysis. Myoglobin is the first enzyme that increases, but returns to normal levels within the first 24 hours after onset of symptoms. CK increases a few hours later, reaches its peak value within the first 24 hours, and remains at these levels for 3 days. Even though the presence of myoglobin in serum is the key feature of rhabdomyolysis, CK is considered to be a more useful marker for the diagnosis and assessment of the severity of muscular injury due to its delayed clearance from the plasma and the wide availability for diagnostic testing. (Reprinted from Giannoglou et a/ ${ }^{80}$ Copyright 2007, with permission from Elsevier).
There is no consensus in the literature concerning the exact level of CK increases required to fulfil the definition of ERM, with suggested CK levels ranging from $>5$, $>10,>20$ or even $>50$ times the upper limit of normal (ULN). ${ }^{2}{ }^{4} 18-20$ There is, however, some agreement that the limit of a CK value of $>5$ times the ULN is very conservative, as it does not take into account documented baseline differences as a function of gender, ethnicity and training levels. ${ }^{18} 2122$ These ULN levels vary considerably: 217 and $414 \mathrm{IU} / \mathrm{L}$ in Caucasian women and men, and 336 and $801 \mathrm{IU} / \mathrm{L}$ in African women and men, respectively. ${ }^{23}$

\section{Physiological exertional CK elevation}

Several studies have investigated the occurrence of rhabdomyolysis among healthy individuals exposed to unaccustomed physical exertion, such as military recruits during basic military training and athletes. ${ }^{20} \quad 24-27$ Kenney et al studied a cohort of 499 healthy individuals who participated in a 2-week basic military training, including eccentric strength training. The cohort included individuals of various ethnicities. The term 'clinically symptomatic ERM' was defined more stringently than the above: elevated serum CK, muscle weakness and myoglobinaemia and/or myoglobinuria. Hence, patients with myalgia in the absence of weakness were not included. Based on this definition, no cases of ERM were encountered. The mean and median CK values were within normal limits (for sex and race) at baseline, peaked with maximal elevation at day 7 and returned to normal at day 14 . Serum CK levels were nearly universally elevated during training, but they were also increased in nearly one-fourth of the participants at baseline. At day 7, 27\% of participants had CK levels $>5$ times the ULN, and $11 \%$ had levels $>10$ times the ULN, with values ranging from 56 to $35056 \mathrm{IU} / \mathrm{L}$ on day 7. There was no correlation whatsoever between CK levels and the amount of exertion, environmental conditions, or myalgia, or weakness. In fact, quite surprisingly, and contrary to received opinion, CK elevations were less pronounced during the hot, humid months. One possible explanation was the less rigorous training during the hot months. ${ }^{20}$ Hence, the authors proposed that patients with serum CK levels $<50$ times the ULN, no definite muscle swelling or weakness, no myoglobinuria, and without laboratory evidence of ARF or electrolyte imbalance have most likely expressed a physiological response to exercise and should not be classified as having 'clinically significant ERM'. ${ }^{20}$ Furthermore, the authors suggested that CK is only one of the factors predicting morbidity and mortality in ERM, which is in line with a recent risk stratification model. $^{28}$

\section{Unaccustomed physical exertion}

A large number of cases and case series have been published, reporting healthy individuals who were exposed to levels of exercise they were not accustomed to. In 
particular, eccentric contractions increase the risk of developing ERM. These exercises are well represented in various extreme conditioning programmes (such as 'CrossFit', 'Insanity', 'Gym Jones'). These programmes typically involve high-volume and high-intensity physical activities with short rest periods between movements and use of multi-joint exercises and therefore require special instructions for trainers and participants. ${ }^{29}$ In endurance exercise such as marathon running, which does not involve eccentric contractions, ERM seems to be less common, and mostly in combination with other factors.

Most often, ERM affects physically untrained persons who overexert themselves, particularly in hot weather. Also, conditioned athletes may experience rhabdomyolysis when they suddenly increase their training volume or intensity or when they begin a new regimen requiring intense eccentric muscle contractions. ${ }^{30}$ Several cases have been reported during preseason training camps taking place after prolonged periods of rest or reduced exercise levels. ${ }^{30} 31$ In fact, ERM may occur to anyone who performs physically 'too much, too fast, too soon of an exercise too novel'. ${ }^{31}$ The cluster of ERM affecting the Division I Football team of Iowa university in 2011 is probably the best known example of the latter. ${ }^{31}$ Two days after a 3-week winter break, the team started an intense training programme, consisting of strenuous strength training including eccentric exercises. Within 1-week, 13 football players were hospitalised with ERM (CK ranging from 96987 to 331044 IU/L). None developed compartment syndrome or problematic renal failure; all were discharged as the symptoms subsided during the next few days. ${ }^{31}$ This event led to the introduction of an obligatory acclimatisation period during the initial days of preseason camps. ${ }^{32}$

Several other studies confirm the high CK increase occurring in healthy individuals during unaccustomed strenuous exercise. ${ }^{33-35} \mathrm{~A}$ study in healthy individuals participating in lengthy marches $(50$ and $80 \mathrm{~km})$ with heavy backload also showed a huge increase of CK during each march, reaching levels 40-fold to 80-fold higher than the typical value for healthy sedentary participants, reflecting ongoing muscle damage. ${ }^{34}$ Recently, Oh et al presented clinical data from 30 previously healthy patients admitted to a military hospital for ERM. The exercise regimens included strength and resistance training, CrossFit training and loaded marches. CK levels ranged between 1565 and $410755 \mathrm{IU} / \mathrm{L}$, and in nine participants CK was above $100000 \mathrm{IU} / \mathrm{L}$. All participants recovered well and no complications were noted at follow-up following discharge from the hospital. ${ }^{27} \mathrm{~A}$ similar increase in rhabdomyolysis events occurred when a swim coach added strenuous push-ups to the usual training routine and when a gym teacher told 119 high school students to do 120 push-ups in 5 min. ${ }^{36}$ Other reports of triceps or biceps rhabdomyolysis have included female lacrosse players, sailors aboard a ship, a physician after a gym workout, a young man after a rowing drill, and research volunteers in a laboratory model of biceps overexertion. ${ }^{37-39}$ Apparently, strength and conditioning coaches are generally well aware of heat injury and dehydration, but not always of the risk of ERM. $^{31}$

\section{Other external or acquired provoking factors}

In addition to unaccustomed physical exercise, other factors contributing to the risk of ERM include inadequate hydration, high ambient temperatures, supplement use (ephedra, creatinine and herbal weight loss supplements) or certain medications (statins, selective serotonin reuptake inhibitors), illicit drug or alcohol use, or recent viral illnesses. This is illustrated by the report of a 31-year-old athlete and physiology professor who experienced an episode of rhabdomyolysis after resistance training, where high intrinsic motivation, mental stress, use of supplements and dehydration were identified as probably additive provoking factors. ${ }^{40}$ Along similar lines, the rare reported cases of rhabdomyolysis with ARF in marathon runners most likely result from the combination of several factors, such as heat stress, dehydration, non-steroidal anti-inflammatory drug or other analgesic use, viral or bacterial infection, and possibly latent myopathies. ${ }^{24}$

Most recently, obstacle races combining aerobic and anaerobic activities performed at different environmental settings (eg, running and/or crawling on mud, diving in freezing water and being exposed to electrical discharges, which are commonly followed by alcohol intake) such as Tough Mudder are becoming popular. ${ }^{41}$ This is associated with various risk factors for rhabdomyolysis such as extenuating exercise, dehydration and exposure to heat, infectious disease, electrical pulses, physical trauma and alcohol consumption. ${ }^{42}$

Furthermore, intense and enthusiastic coaching or challenge by peers is the force that drives the already highly motivated professional or recreational athletes beyond their limit of exertion in many cases. This includes sports teams, as well as inmates in prison and soldiers. ${ }^{27} 43-45$

\section{Symptoms of CK increase}

In many patients, early, uncomplicated rhabdomyolysis is subtle, with delayed-onset myalgia and localised oedema being the only noted symptoms. Myalgia typically occurs 12-36 hours after the exercise. In a minority of patients, generalised weakness and myoglobinuria are the presenting symptoms. However, not all patients present with this classic triad. Other symptoms include fatigue, nausea, vomiting and fever. In severe cases, patients may have delirium and oliguria. Muscle pain and weakness can continue during and after recovery from rhabdomyolysis. In theory, an inflammatory myopathy may occur with subsequent fibrosis of muscle tissue. ${ }^{46}$ If the patient is asymptomatic with a persistent and stable raised CK, consider an underlying neuromuscular condition such as muscular dystrophy (table 1). 
Table 1 Genetic disorders with increased risk (or lowered threshold) of exertional rhabdomyolysis

\section{Symptoms onset: timely relation to} exercise

\section{Type of exercise that} may trigger RM

Aerobic exercise Anaerobic exercise

Strenuous exercise

Few minutes

Disorders of glycogen

metabolism

PYGM, PFKM, ENO3,

PGAM2, PGK1, PGM1,

PHKA1, PHKB
Disorders of long-chain fatty acid metabolism ACADVL, CPT2, ETFA, ETFB, ETFDH, MTP
Later onset (Usually >45 $\mathrm{min}$ to hours)

\section{Unspecified}

\section{COI (MTCO1), COII \\ (MTCO2), COIII (MTCO3),}

FDX1 L, HADHA, HADHB,

ISCU, MTCYB, IIDNA
Prolonged aerobic exercise

Prolonged or repetitive exercise

Strenuous exercise Unspecified

Diagnostic clue ${ }^{\star}$

creased baseline CK level, vacuolar myopathy with glycogen accumulation (muscle biopsy), blunted increase in lactate in forearm exercise test (except: PHKA1, PHKB)

PYGM: second-wind phenomenon PFKM: 'out-of-wind phenomenon', polyglucosan bodies (muscle biopsy) PGAM2: tubular aggregates (muscle biopsy)

PGK1: central nervous system symptoms PGM1: multisystem features Haemolytic anaemia: PFKM, PGK1

Symptoms are not triggered by isometric muscle contraction

Abnormal fasting blood acylcarnitine profile

Fasting and catabolic stress may trigger RM ETFA, ETFB, ETFDH: metabolic acidosis Peripheral neuropathy in MTP deficiency Multisystem features

Abnormal muscle biopsy (ragged red fibres, COX-negative fibres) Autosomal recessive or maternal inheritance iron-sulfur cluster assembly enzyme: iron accumulation (muscle biopsy) $\mathrm{RM}$ is exceptional in MMs and FAO disorders should be excluded before considering an $\mathrm{MM}$.

Associated triggers (eg, hot weather), muscle hypertrophy, heat intolerance

Strenuous exercise

Exercise performed in combination with different triggers

Exercise (unspecified)

Moderate intensity of endurance activity

Prolonged intense exercise Moderate physical activity Weightlifting

Unspecified

Unspecified

Increased baseline CK level, gender (DMD)

Muscle rippling, PIRCs

Minutes to a few

BMD or carrier state) $)^{57}$

$D M D$

Other genetic conditions

Sickle cell trait

During or immediately after exercise. A few hours following exercise.
Combination of intense sustained exercise in association with sickle cell trait-related RM triggers
African descent

Risk of sudden death

Unspecified: symptoms may occur during or after exertion; little information about type of physical activilty is available in literature. ${ }^{*}$ The absence of a diagnostic clue does not exclude the diagnosis in some of the reported conditions.

BMD, Becker muscular dystrophy; CK, creatine kinase; COX, cytochrome c oxidase; DMD, Duchenne muscular dystrophy; KDS, King-Denborough syndrome; LGMDs, limb-girdle muscular dystrophies; MHS, malignant hyperthermia susceptibility; MM, mitochondrial myopathy; PIRCs, percussion-induced rapid muscle contractions; RM, rhabdomyolysis; RYR1, type 1 ryanodine receptor. 


\section{Myoglobinuria and ARF}

Myoglobinuria is defined as the presence of myoglobin in the urine, usually associated with rhabdomyolysis or traumatic muscle injury. Myoglobin is the first enzyme that increases in plasma, but, because under physiological circumstances it is readily filtered by the glomerulus and rapidly cleared from the serum into the urine, it normally returns to normal levels within the first 24 hours after symptom onset. However, when large amounts of myoglobin enter the renal tubule lumen, it interacts with the Tamm-Horsfall protein and precipitates, a process enhanced in the presence of acidic urine. Visible myoglobinuria (tea-coloured or colacoloured urine) occurs when urinary myoglobin exceeds $250 \mu \mathrm{g} / \mathrm{mL}$ (normal $<5 \mathrm{ng} / \mathrm{mL}$ ), corresponding to the destruction of more than $100 \mathrm{~g}$ of muscle. ${ }^{47}$ Tubule obstruction principally occurs at the level of the distal tubule. In addition, reactive oxygen species generated by damage to both muscle and kidney epithelial cells promote the oxidation of ferrous oxide to ferric oxide, thus generating a hydroxyl radical. Both the heme moieties and the free iron-driven hydroxyl radicals may be critical mediators of direct tubule toxicity, which mainly occurs in the proximal tubule. A higher volume of urine flow and a higher urine alkalinity prevent myoglobin from precipitating as readily as it would otherwise do.

Myoglobinuria causes little or no morbidity or mortality unless it is associated with the secondary complications of rhabdomyolysis, including hyperkalaemia, hypocalcaemia and acute kidney injury. In adults, the reported ARF incidence in patients with rhabdomyolysis was reported to vary from $4.7 \%$ to $94 \%$ in a recent review. This variation is likely to be at least partly due to the differing definitions of rhabdomyolysis and ARF, and to the differences in number and types of patients evaluated. ${ }^{48}$ In the paediatric age group, although previous small case series reported ARF rates of $40-50 \%$, a large retrospective review indicates that only about $5 \%$ of participants with rhabdomyolysis develop acute kidney injury. ${ }^{49} \mathrm{CK}$ level is only one of the many determinants of renal failure, including comorbidities, use of certain medications, alcohol or illicit drugs and concomitant electrolyte disturbances. ${ }^{28}$

\section{Natural course of ERM}

Among young, physically active patients, the incidence of ERM is low, as is the risk of recurrence. Furthermore, ERM is associated with lower complication rates compared with other causes of rhabdomyolysis, probably because participants do not have other associated diseases or do not take potentially myotoxic treatments. This was shown in a retrospective case series, including population-based and cohort-based analyses in a cohort of 177 patient with rhabdomyolysis at a US army medical centre. ${ }^{25}$ There were 44 cases of ERM from a population of 198399 total military trainees over the study period, or 22.2 cases per 100000 per year. This was one-third of all cases of rhabdomyolysis in this period; other causes included trauma, use of toxins, infection and heat illness. During the follow-up period (ranging from 20 to 60 months, with a mean of 31.2 months) with return to prior levels of physical activity, there was one recurrence of rhabdomyolysis (at 1-month, following exertion). ${ }^{25}$ Hence, long-term risk of recurrence is low. Other reports, including that concerning the football team cited above, also show that the prognosis of ERM without systemic complications is very good. ${ }^{20}$ In general, in the young, healthy population performing sports at an intensity that may cause rhabdomyolysis, complication rate is expected to be low. ${ }^{28}$

\section{Genetic factors with increased risk for ERM}

In addition, several genetic disorders increase the risk of developing ERM. These include metabolic myopathies, disorders of calcium homoeostasis and other structural myopathies, and the sickle cell trait (table 1). RYR1 mutations have been recently recognised to account for a substantial proportion of patients presenting with ERM. ${ }^{3}$ Mutations in this gene are a common cause of neuromuscular disease, ranging from various congenital myopathies to the MHS trait without associated weakness. Associated clinicopathological features in RYRl-associated ERM may be subtle and require a high degree of suspicion. Additional family studies are paramount in order to identify potentially $\mathrm{MH}$-susceptible relatives. $^{3} 5051-53$

Remarkably, some genetic disorders lower the threshold for developing rhabdomyolysis and may also be associated with greater athletic abilities. This is likely to be the case for $R Y R 1$ mutations, in addition to what has been reported regarding variants/polymorphisms in the $A C E$ and $\alpha$-actinin-3 (ACTN3) genes. ${ }^{54-56}$ In other rare situations, a combination of two genetic disorders may alleviate exercise-related phenotypes such as the coexistence of $\alpha$-thalassaemia and sickle cell trait, lowering risk for exercise collapse associated with the sickle cell trait (ECAST) ${ }^{57}$

Emerging evidence suggests that specific polymorphic variants in a number of genes also increase the susceptibility of developing ERM (table 2). For example, the ACTN3 $\mathrm{XX}$ genotype is associated with changes in muscle function as per the structural, metabolic and signalling role played by ACTN3, which might increase the susceptibility to muscle damage, especially due to eccentric exercise. ${ }^{58} 59$ Single nucleotide polymorphisms of the $C K$ muscle-specific $(C K-M M)$ isoform and myosin light chain kinase 2 (MYLK2) genes were also found in significantly higher frequencies in patients who presented with severe episodes of ERM. ${ }^{60}$ However, in the reported study, the authors did not specify the other genetic causes of rhabdomyolysis that had been investigated as part of the diagnostic workup. Moreover, the patients and control groups were not exposed to the same amount of exercise, and possible provoking factors were not considered. Further studies will be required to determine the molecular mechanism(s) whereby these 
Table 2 Genes with polymorphic variants previously reported in association with increased susceptibility to ERM or exercise heat tolerance

\begin{tabular}{|c|c|c|c|c|c|}
\hline Gene & $\begin{array}{l}\text { Exercise-related } \\
\text { increased CK }\end{array}$ & $\begin{array}{l}\text { Exercise-related } \\
\text { muscle damage }\end{array}$ & $\begin{array}{l}\text { Other features/study } \\
\text { sample }\end{array}$ & $\begin{array}{l}\text { Type of } \\
\text { exercise that } \\
\text { triggered } \\
\text { muscle } \\
\text { symptoms }\end{array}$ & $\begin{array}{l}\text { Differential } \\
\text { diagnosis for } \\
\text { well-known } \\
\text { genetic causes } \\
\text { of RM }\end{array}$ \\
\hline $\begin{array}{l}A C E \\
\|>\mid D>D D^{72}\end{array}$ & Yes & NK & $\begin{array}{l}\text { Healthy young } \\
\text { volunteers; CK } \\
\text { assessed pre, } 3,24,48 \text {, } \\
72,96,120 \text { and } \\
168 \text { hours postexercise }\end{array}$ & $\begin{array}{l}\text { Strenuous } \\
\text { eccentric } \\
\text { contractions }\end{array}$ & NK \\
\hline $\begin{array}{l}\text { ACTN3 } \\
\mathrm{R}^{2} 77 \mathrm{X}^{60}\end{array}$ & NK & $\begin{array}{l}\text { Previous history } \\
\text { of severe ERM }\end{array}$ & $\begin{array}{l}\text { Control group and } \\
\text { affected patients did not } \\
\text { perform the same } \\
\text { amount of exercise }\end{array}$ & NK & $\begin{array}{l}\text { A detailed list } \\
\text { containing the } \\
\text { investigated } \\
\text { disorders in people } \\
\text { with ERM was not } \\
\text { provided. }\end{array}$ \\
\hline $\begin{array}{l}\text { ACTN3 } \\
\text { R577X }^{73}\end{array}$ & Yes & NK & $\begin{array}{l}\text { Cortisol, testosterone, } \\
\text { IL- } 6, \alpha \text {-actin and CK } \\
\text { assessed pre, } \\
\text { immediately after, } 2 \text { and } \\
4 \text { hours postexercise } \\
\text { Professional athletes }\end{array}$ & Eccentric & NK \\
\hline $\begin{array}{l}\text { CCL2 } \\
\text { rs3917878 }\end{array}$ & Yes (women) & $\begin{array}{l}\text { Attenuated } \\
\text { strength recovery } \\
\text { (men) }\end{array}$ & $\begin{array}{l}\text { Blood samples from a } \\
\text { previous clinical trial on } \\
\text { topical non-steroidal } \\
\text { anti-inflammatory } \\
\text { CK assessed pre, } 4,7 \\
\text { and } 10 \text { days } \\
\text { postexercise }\end{array}$ & $\begin{array}{l}\text { Strenuous } \\
\text { eccentric } \\
\text { contractions }\end{array}$ & NK \\
\hline $\begin{array}{l}\text { CCR2 } \\
\text { rs3918358 } \\
\text { rs1799865 }\end{array}$ & Likely & $\begin{array}{l}\text { Slower recovery } \\
\text { (women- } \\
\text { rs3918358) and } \\
\text { soreness } \\
\text { (rs1799865) }\end{array}$ & $\begin{array}{l}\text { Blood samples from a } \\
\text { previous clinical trial on } \\
\text { topical non-steroidal } \\
\text { anti-inflammatory } \\
\text { CK assessed pre, } 4,7 \\
\text { and } 10 \text { days } \\
\text { postexercise }\end{array}$ & $\begin{array}{l}\text { Strenuous } \\
\text { eccentric } \\
\text { contractions }\end{array}$ & NK \\
\hline $\begin{array}{l}M Y L K \\
49 T^{75}\end{array}$ & Yes & No & $\begin{array}{l}\text { Blood samples from a } \\
\text { previous clinical trial on } \\
\text { topical non-steroidal } \\
\text { anti-inflammatory } \\
\text { CK assessed pre, } 4,7 \\
\text { and } 10 \text { days } \\
\text { postexercise } \\
\text { Higher baseline strength }\end{array}$ & $\begin{array}{l}\text { Strenuous } \\
\text { eccentric } \\
\text { contractions }\end{array}$ & NK \\
\hline $\begin{array}{l}\text { MYLK } \\
\text { C37885A }^{75}\end{array}$ & Yes & $\begin{array}{l}\text { Postexercise } \\
\text { strength loss }\end{array}$ & $\begin{array}{l}\text { Blood samples from a } \\
\text { previous clinical trial on } \\
\text { topical non-steroidal } \\
\text { anti-inflammatory } \\
\text { CK assessed pre, } 4,7 \\
\text { and } 10 \text { days } \\
\text { postexercise }\end{array}$ & $\begin{array}{l}\text { Strenuous } \\
\text { eccentric } \\
\text { contractions }\end{array}$ & NK \\
\hline $\begin{array}{l}\text { MYLK } \\
\text { C37885A }\end{array}$ & NK & $\begin{array}{l}\text { Previous history } \\
\text { of severe ERM }\end{array}$ & $\begin{array}{l}\text { Control group and } \\
\text { affected patients did not } \\
\text { perform the same } \\
\text { amount of exercise }\end{array}$ & NK & $\begin{array}{l}\text { A detailed list } \\
\text { containing the } \\
\text { investigated } \\
\text { disorders in people } \\
\text { with ERM was not } \\
\text { provided. } \\
\end{array}$ \\
\hline
\end{tabular}


Table 2 Continued

\begin{tabular}{|c|c|c|c|c|c|}
\hline Gene & $\begin{array}{l}\text { Exercise-related } \\
\text { increased CK }\end{array}$ & $\begin{array}{l}\text { Exercise-related } \\
\text { muscle damage }\end{array}$ & $\begin{array}{l}\text { Other features/study } \\
\text { sample }\end{array}$ & $\begin{array}{l}\text { Type of } \\
\text { exercise that } \\
\text { triggered } \\
\text { muscle } \\
\text { symptoms }\end{array}$ & $\begin{array}{l}\text { Differential } \\
\text { diagnosis for } \\
\text { well-known } \\
\text { genetic causes } \\
\text { of RM }\end{array}$ \\
\hline$C K-M M \mathrm{Ncol}^{60}$ & NK & $\begin{array}{l}\text { Previous history } \\
\text { of severe ERM }\end{array}$ & $\begin{array}{l}\text { Control group and } \\
\text { affected patients did not } \\
\text { perform the same } \\
\text { amount of exercise }\end{array}$ & NK & $\begin{array}{l}\text { A detailed list } \\
\text { containing the } \\
\text { investigated } \\
\text { disorders in people } \\
\text { with ERM was not } \\
\text { provided. }\end{array}$ \\
\hline$C K-M M \mathrm{Ncol}^{76}$ & Yes & NK & $\begin{array}{l}\text { Healthy volunteers ( } 86 \% \\
\text { Caucasians); CK } \\
\text { assessed immediately, } \\
48 \text { and } 72 \text { hours } \\
\text { postexercise }\end{array}$ & $\begin{array}{l}\text { Short duration } \\
\text { ( } 6 \text { min), } \\
\text { moderate } \\
\text { intensity, mostly } \\
\text { anaerobic } \\
\text { exercise }\end{array}$ & NK \\
\hline $\begin{array}{l}\text { IGF-II } \\
\text { rs3213221 } \\
\text { rs680 }\end{array}$ & Yes & $\begin{array}{l}\text { Strength loss and } \\
\text { soreness }\end{array}$ & $\begin{array}{l}\text { Blood samples from a } \\
\text { previous clinical trial on } \\
\text { topical non-steroidal } \\
\text { anti-inflammatory } \\
\text { CK assessed pre, } 4,7 \\
\text { and } 10 \text { days } \\
\text { postexercise } \\
\text { Women: no association }\end{array}$ & $\begin{array}{l}\text { Strenuous } \\
\text { eccentric } \\
\text { contractions }\end{array}$ & NK \\
\hline $\begin{array}{l}\text { IGF2AS } \\
\mathrm{A} 1364 \mathrm{C}^{77}\end{array}$ & Yes & $\begin{array}{l}\text { Strength loss and } \\
\text { soreness }\end{array}$ & $\begin{array}{l}\text { Blood samples from a } \\
\text { previous clinical trial on } \\
\text { topical non-steroidal } \\
\text { anti-inflammatory } \\
\text { CK assessed pre, } 4,7 \\
\text { and } 10 \text { days } \\
\text { postexercise } \\
\text { Women: no association }\end{array}$ & $\begin{array}{l}\text { Strenuous } \\
\text { eccentric } \\
\text { contractions }\end{array}$ & NK \\
\hline $\begin{array}{l}\text { IL-6 } \\
\mathrm{G} 174 \mathrm{C} \\
\mathrm{CC}>\mathrm{GC}>\mathrm{GG}^{78}\end{array}$ & Yes & NK & $\begin{array}{l}\text { Healthy young } \\
\text { volunteers; CK } \\
\text { assessed pre, } 3,24,48 \text {, } \\
72,96,120 \text { and } \\
168 \text { hours postexercise }\end{array}$ & $\begin{array}{l}\text { Strenuous } \\
\text { eccentric } \\
\text { contractions }\end{array}$ & NK \\
\hline TNFA G308A 78 & Yes (GG) & NK & $\begin{array}{l}\text { Healthy young } \\
\text { volunteers; CK } \\
\text { assessed pre, } 3,24,48 \text {, } \\
72,96,120 \text { and } \\
168 \text { hours postexercise }\end{array}$ & $\begin{array}{l}\text { Strenuous } \\
\text { eccentric } \\
\text { contractions }\end{array}$ & NK \\
\hline$R Y R 1^{5279}$ & Inconsistent & Inconsistent & $\begin{array}{l}\text { Susceptibility to } \mathrm{MH} \\
\text { muscle weakness (CCD) }\end{array}$ & & \\
\hline
\end{tabular}

variants confer a real risk. The use of new diagnostic techniques such as next generation sequencing and whole exome sequencing in large samples of patients with recurrent rhabdomyolysis in conjunction with functional studies may be more appropriate to identify genuine 'rhabdomyolysis susceptibility genotypes'.

\section{CLINICAL APPROACH}

The clinical approach of patients with ERM consists of 4 steps: (1) Is the ERM clinically significant, requiring hospital admission and intravenous fluid administration? (2) What is the risk of developing ARF? (3) Is the ERM the (first) manifestation of a genetic disorder? And (4) when and how to restart exercise and sporting activities?

\section{Step 1: is the ERM clinically significant?}

The first step when encountering a patient with a high CK after strenuous exercise is to determine whether the rhabdomyolysis is clinically significant, requiring hospital admission and intravenous fluid administration. There 
are no compelling randomised controlled trials offering concrete management guidelines for this question or other aspects of rhabdomyolysis treatment. However, the study of Kenney et al reporting many cases of physiological ERM offers a practical guideline for this first step (which includes laboratory investigations for renal function and electrolytes) by demonstrating that patients with a $\mathrm{CK}<50$ times the ULN, with absence of muscle weakness or swelling, no myoglobinuria and normal renal function and electrolytes are very likely to have a physiological ERM episode. ${ }^{20}$ For clarity and to be on the safe side, we propose the CK level of $10000 \mathrm{IU} / \mathrm{L}$
( $\sim 50$ times the ULN of white women) as a cut-off point for assessment at the emergency room (table 3). ${ }^{20} 61$ The goals of inpatient or outpatient treatment are to avoid renal injury, prevent further muscle injury and avoid complications of electrolyte disturbances (box 1).

\section{Step 2: what is the risk of developing ARF?}

The second step takes place during evaluation in the emergency room, and concerns the assessment of the risk of ARF and mortality, according to a recently developed algorithm, which shows that the risk of ARF increases with a $\mathrm{CK}>40000 \mathrm{IU} / \mathrm{L}^{28}$ Other risk factors

Table 3 Selection of patients who require hospital admission and intravenous fluid administration

\begin{tabular}{|c|c|c|}
\hline & Physiological ERM & Clinically significant ERM \\
\hline Clinical features & Only myalgia & $\begin{array}{l}\text { Also muscle weakness and/or swelling and/or } \\
\text { altered consciousness }\end{array}$ \\
\hline Vital signs & Normal & $\begin{array}{l}\text { Abnormal and/or body temperature }>40^{\circ} \mathrm{C} \\
\text { (heat stroke) }\end{array}$ \\
\hline Exercise & Clearly unaccustomed & Accustomed/unaccustomed \\
\hline CK (U/L) & $<10000$ & $\geq 10000$ \\
\hline Myoglobinuria/myoglobinaemia & Absent & Present \\
\hline Acute renal failure & Absent & Absent or present \\
\hline Electrolyte abnormalities & Absent & Absent or present \\
\hline Acid base status & Normal & Abnormal \\
\hline $\begin{array}{l}\text { Other factors possibly provoking } \\
\text { rhabdomyolysis }\end{array}$ & Absent & Absent or present \\
\hline \multirow[t]{2}{*}{ History } & $\begin{array}{l}\text { No prior episodes of ERM } \\
\text { No other indicators of NMD } \\
\text { No renal, cardiac or pulmonary } \\
\text { medical comorbidity }\end{array}$ & $\begin{array}{l}\text { Prior episodes of ERM } \\
\text { Other indicators of NMD } \\
\text { Renal, cardiac or comorbidity }\end{array}$ \\
\hline & Outpatient follow-up if all normal & $\begin{array}{l}\text { Referral to the ER in case of any of these } \\
\text { factors }\end{array}$ \\
\hline
\end{tabular}

\section{Box 1 Management of exertional rhabdomyolysis (ERM)}

Outpatient follow-up of patients with physiological ERM ${ }^{18}$

- Rest for 72 hours and encourage oral hydration

- Sleep 8 hours consecutively, nightly

- Remain in thermally controlled environment if ERM occurred in association with heat injury

- Refer to ERM in case temperature exceeds $40^{\circ} \mathrm{C}$

- Follow-up in 72 hours for repeat creatine kinase (CK) and blood urea:

- CK<5xupper limit of normal (ULN) and normal blood urea: no further studies

- Return every 72 hours and repeat until CK<5xULN and normal blood urea

- $C K \geq 5 \times U L N$ or abnormal blood urea for $>2$ weeks: refer for expert consultation

- CK $\geq 50 \times U L N(10000 \mathrm{U} / \mathrm{L})$ : refer to ERM again

- Refrain from sports

Elimination of medications, drugs and toxins that are considered to cause rhabdomyolysis

Clinical management of patients with clinically significant rhabdomyolysis ${ }^{4} 4862$

- Hyperhydration: Intravenous fluids should be initiated as soon as possible, preferably within the first 6 hours after muscle injury, at a rate that maintains a urine output in adults of $\geq 300 \mathrm{~mL} /$ hours for at least the first 24 hours

- Admit at an ICU and consider peritoneal dialysis or haemodialysis in patients with little or no urine output despite hyperhydration, profound acidosis or severe hyperkalaemia

- Mannitol should be administered only to maintain urine output of $300 \mathrm{~mL} / \mathrm{h}$ or more despite adequate fluid administration

- Sodium bicarbonate should be administered only if necessary to correct systemic acidosis

- Elimination of medications, drugs and toxins that are considered to cause rhabdomyolysis 
are age $>50$ years, female sex, initial creatinine $>1.4 \mathrm{mg}$ / $\mathrm{dL}$ and additional metabolic changes (hypocalcaemia, hyperphosphataemia, decreased bicarbonate) (table 4). The ability to identify these patient early in the course of a rhabdomyolysis episode is useful for early institution of aggressive prophylactic measures, admission to the ward or intensive care unit, and communication with patients and families about prognosis. Scharmann has summarised the available evidence concerning therapies to prevent kidney injury in rhabdomyolysis. ${ }^{48}$

In general, serial physical and laboratory examinations are necessary to manage patients with ERM appropriately. ${ }^{4}$ In the acute phase, treatment should be aimed at preserving renal function and restoring metabolic derangements. Early and adequate volume replacement with isotonic sodium chloride solution $0.9 \%$ (no potassium-containing or lactate-containing solutions) may directly prevent renal injury by aiding clearance of toxic substances and increasing renal perfusion pressure. Volume expansion increases renal blood flow and, consequently, glomerular filtration and urination. A common goal of treatment is to achieve a urine output of $300 \mathrm{~mL} /$ hour. This may require infusion of intravenous fluids by $1-2 \mathrm{~L} /$ hour until urine output is stable. Intravenous fluid should preferably be continued until serum CK activity in plasma has declined to $1000 \mathrm{IU} / \mathrm{L}$

Table 4 Assessment of risk of acute renal failure and other complications

\begin{tabular}{|c|c|}
\hline & Diagnostic tests used in the evaluation of rhabdomyolysis \\
\hline General examination & $\begin{array}{l}\text { Assess the level of consciousnessCheck for signs of: } \\
\text { Dehydration } \\
\text { Systemic infection } \\
\text { Trauma } \\
\text { Compartment syndrome } \\
\text { Exertion heat stroke }\end{array}$ \\
\hline History & $\begin{array}{l}\text { Check medication use } 62 \\
\text { Antipsychotics (haloperidol, fluphenazine, perphenazine, chlorpromazine) } \\
\text { Cyclic antidepressants and selective serotonin reuptake inhibitors } \\
\text { Statins (atorvastatin, fluvastatin, lovastatin, pravastatin, rosuvastatin, simvastatin, cerivastatin) } \\
\text { - Fibric acid derivatives (bezafibrate, clofibrate, fenofibrate, gemfibrozil) } \\
\text { Quinine } \\
\text { Salicylates } \\
\text { - Theophylline } \\
\text { Antibiotics (fluoroquinolones, pyrazinamide, trimethoprim/sulphonamide, amphotericin B, } \\
\text { itraconazole, levofloxacin) } \\
\text { Zidovudine } \\
\text { Antihistamines } \\
\text { Aminocaproic acid } \\
\text { Phenylpropanolamine } \\
\text { Sodium valproate } \\
\text { Anaesthesia with volatile anaesthetics a/o succinylcholine } \\
\text { Benzodiazepines } \\
\text { Corticosteroids }\end{array}$ \\
\hline Vital signs & Check for signs of hypovolaemia and shock \\
\hline Serum CK & Elevated as a result of muscular damage: $>5,>10,>20$ or even $>50$ times the ULN \\
\hline Serum potassium & $\begin{array}{l}\text { Elevated levels indicate muscular damage and potassium leakage from cells } \\
\text { Hyperkalaemia increases the patient's risk for dysrhythmias }\end{array}$ \\
\hline Serum sodium & Check for exercise-associated hyponatraemia \\
\hline Renal function & $\begin{array}{l}\text { Blood urea nitrogen and serum creatinine-assess renal function and hydration status. } \\
\text { An elevated ratio may suggest dehydration, and an elevated creatinine level may suggest renal } \\
\text { dysfunction. }\end{array}$ \\
\hline Myoglobinuria & $\begin{array}{l}\text { Presence of urine myoglobin suggests muscular damage } \\
\text { Absence of urine myoglobin does not preclude exertional rhabdomyolysis } \\
\text { (optional; CK levels are normally used to guide management) }\end{array}$ \\
\hline Acid base status & Check for metabolic acidosis \\
\hline Coagulation tests & Abnormal results may indicate disseminated intravascular coagulation \\
\hline ECG & Check for dysrhythmias if the patient has hyperkalaemia or other electrolyte abnormalities \\
\hline Cardiac isoenzymes & Rule out cardiac infarction \\
\hline Toxicology screening & Check blood and urine for (illicit) drug abuse \\
\hline Risk assessment & $\begin{array}{l}\text { Use the 'Risk prediction score for kidney failure or mortality in rhabdomyolysis' by McMahon } \\
\text { et al. }{ }^{28}\end{array}$ \\
\hline
\end{tabular}


or below. In patients with little or no urine output despite aggressive hydration, profound acidosis or severe hyperkalaemia, consider peritoneal dialysis or haemodialysis and consult a nephrologist. Aggressive hydration may not be appropriate in patients with other comorbidities such as heart failure. Furthermore, if kidney injury is already established, overly aggressive hydration in a patient with already established renal failure may lead to volume overload and pulmonary oedema.

Mannitol leads to an increase in blood flow and glomerular filtration, which reduces the obstruction by myoglobin casts. It must only be given after volume replacement and must be avoided in patients with oliguria. It is not routinely recommended, but may be administered if the target urine output cannot be achieved by other means. Loop diuretics have also been investigated, but published data are too limited to support recommending them routinely. Although not proven by randomised control trials, some experts recommend the addition of bicarbonate. Alkalisation of the urine (target $\mathrm{pH}$ 6.5) promotes myoglobulin washout and corrects the metabolic acidosis and hyperkalemia. A recent systematic review has shown that sodium bicarbonate should only be administered to patients with systemic acidosis. ${ }^{48}$

Monitoring for and treating rhabdomyolysis-related electrolyte abnormalities is an important part of managing patients with ERM. Hyperkalaemia, hypocalcaemia, hyperphosphataemia and hyperuricaemia are common in patients with rhabdomyolysis, and should be treated with standard therapy. Although hypocalcaemia is common in early rhabdomyolysis, hypercalcaemia can occur later. Calcium supplementation should only be prescribed for patients with symptomatic hypocalcaemia or severe hyperkalaemia. More research is needed to determine whether allopurinol may be useful for preventing ERM and acute renal damage. ${ }^{13}$

Compartment syndrome requires surgical consultation. If the compartment pressure measured by an intramuscular needle exceeds $50 \mathrm{~mm} \mathrm{Hg}$, or if pressure persists between 30 and $50 \mathrm{~mm} \mathrm{Hg}$ for longer than 6 hours, decompressive fasciotomy must be considered. ${ }^{63}$ Haemorrhagic complications in patients with disseminated intravascular coagulation (DIC) and rhabdomyolysis require careful management. Drugs and toxins should be eliminated (eg, haemodialysis/antidotes) if possible. Anaesthetic precautions (such as avoidance of depolarising muscle relaxants and volatile anaesthetics) should be taken in patients with an ongoing rhabdomyolysis. Anaesthetic precautions are also suggested for undiagnosed patients with strong evidence of an underlying RYR1-related rhabdomyolysis episode and of course for MHS patients and their relatives.

\section{Step 3: is the ERM the (first) manifestation of a genetic disorder?}

Several studies and reviews have focused on the underlying genetic causes of (exertional) rhabdomyolysis. ${ }^{6-9} 64$
However, the key questions are: in which patients should an underlying genetic disorder be considered, and hence which patients should be referred for a more specialist neuromuscular consultation after the recovery from the initial rhabdomyolysis episode?

In general, 'benign ERM' is the final conclusion if no underlying genetic cause is detected after several diagnostic studies. ${ }^{6}$ However, in order to prevent unnecessary invasive diagnostic procedures, it would be better to start with an assessment of the risk of an underlying disorder. Landau et $a l^{8}$ proposed an algorithm for both acute management and follow-up. This includes selection criteria for patients to be referred for further evaluation for and underlying genetic (neuromuscular) disease. The criteria proposed are in line with those in other reviews: 'persistent hyperCKemia or weakness 4 weeks after the event'; 'a (family) history of exercise-induced, fasting-induced or fever-induced rhabdomyolysis or malignant hyperthermia', and the 'presence of exertional muscle cramps or exercise intolerance'.

We suggest a few additional clinical indicators, based on the risk for recurrence assessment proposed by O'Connor et $a l^{18}{ }^{18}$ the high-risk criteria brought up by Szczepanik and our own experience. ${ }^{65}$ The first clinical indicator is 'rhabdomyolysis in case of accustomed exercise': if the rhabdomyolysis occurs in a trained athlete who has worked out at a level of intensity that he is used to (in the absence of other provoking factors), the exercise is not 'unaccustomed'. The absence of team-related cases of ERM also points to the exercise that was not unaccustomed to the level of physical fitness. In these cases, there is a greater likelihood of finding an underlying genetic cause. A genetic cause is also more likely when different members of the same family suffer a rhabdomyolysis event simultaneously, for example, during the same intermittent viral illness or during the same sports event, ${ }^{366}$ or when onset is in childhood. Finally, an underlying genetic condition should be suspected in patients in whom exercise is the only underlying cause, or in whom other exogenous causes (drugs, medication (including anaesthesia), infection) seem insufficient to explain the severity of the rhabdomyolysis episode. $^{2} 40$

In order to improve the recognition of patients with an increased risk, we propose the use of the acronym ' $R H A B D O$ ': screening for a genetic cause should be considered if any of the criteria below are present (table 5).

We refer to table 1 and recent detailed reviews for an overview of genetic disorders to be considered. ${ }^{6-9}$

\section{Step 4: when and how to recommence exercise and sporting activities?}

No evidence-based guidelines concerning return to physical activity after ERM are currently available. The natural course of ERM in cases without suspicion of a genetic disorder suggests that return to sports is safe. ${ }^{25}$ During follow-up (ranging from 20 to 60 months, with a 
mean of 31.2 months), there was only one recurrence of rhabdomyolysis (at 1-month, following exertion) in this cohort, yielding a recurrence risk of $0.08 \%$ per person per year. ${ }^{25}$ Several expert opinion guidelines advise

Table 5 Selection of patients for screening of a genetic disorder

\section{Consider a genetic cause of the exertional rhabdomyolysis in case of 'RHABDO'}

R Recurrent episodes of exertional rhabdomyolysis

H HyperCKaemia persists 8 weeks after the event

A Accustomed physical exercise

B Blood CK $>50 \times$ ULN ( $>10000$ ULN in female Caucasian patients)

D Drugs/medication/supplements and other exogenous and endogenous factors cannot sufficiently explain the rhabdomyolysis severity

O Other family members affected/Other exertional symptoms (cramps, myalgia)

CK, creatine kinase; ULN, upper limit of normal. refraining from sports for at least 4 weeks, until the CK has normalised, and then begin light activities (box 2).

O'Connor et $a l^{18}$ suggests three phases of return to physical exercise for athletes who are not at risk: phase 1: onset to normalisation of CK to $<5$ times the ULN; phase 2: start of light activities; phase 3: gradually return to regular sporting activities and physical training (guideline evolved from the Rhabdomyolysis Working Group at the Consortium for Health and Military Performance (CHAMP)).

\section{CONCLUSION}

We have presented an overview of clinical and diagnostic aspects of ERM, in a stepwise approach. At each step, it is important to distinguish normal physiological reactions from ERM as the first manifestation of a genetic disorder. It is essential for physicians working at the 'physiological' end (sports medicine/military medicine) and those working at the clinical end of the medical spectrum (emergency medicine, internal medicine,

\section{Box 2 Guideline to restart exercise and sporting activities}

Advice to restart sport $>4$ weeks of the event and patient is asymptomatic

Patients without suspicion of a genetic disorder

- Begin light but no strenuous physical activities

- Follow-up with physician in 1-week

- In case of clinical symptoms (muscle weakness, swelling or myalgia) remain in start schedule and return at 1-week intervals

- Only if no clinical symptoms (muscle weakness, swelling or myalgia) return, gradually increase the intensity and duration

- Avoid unaccustomed exercise, especially eccentric training

Follow-up with care provider as needed

\section{Patients with (suspicion of) a genetic disorder in general}

Additional advices:

- Search help of a physical therapist/sports medicine specialist/rehabilitation specialist with expertise of training in inherited myopathies

- Wear an SOS necklace

- Very gradual return to a less-intense training schedule

- Strictly avoid the combination of strenuous exercise with other risk factors for rhabdomyolysis (drugs, medication, supplements, viral infection)

- Strictly avoid unaccustomed exercise, especially eccentric training

- Prevent dehydration during exercise

- Do limit training intensity in hot and humid environment

- Report to physician in case of exertional myalgia and perform creatine kinase check-up

Additional advice in case of metabolic myopathies:

- Prevent fasting

- Avoid sugar intake just before exercising (Tarui disease)

- Getting into the second wind phenomenon routinely (McArdle disease)

- Avoid exercising if catabolic stress; eg, infection (fatty acid oxidation disorders)

Additional advice in case of type 1 ryanodine receptor (RYR1)-related exertional rhabdomyolysis:

- Prevent the combination of extreme heat exposure and strenuous exercise

- Do not use caffeine or other supplements

- Limit alcohol consumption in periods of intense sport activities

Additional advice in case of sickle cell trait.

- Patient should be asymptomatic

- Prevent dehydration before, during and after exercise

- Do not use caffeine, other supplements or drugs prior to exercise without medical advice

- Avoid exercising in the presence of other triggers for sickle cell trait-related rhabdomyolysis (hot and humid weather, high altitude, concomitant infection, etc) ${ }^{67}$

Assess previous history of exercise collapse associated with sickle cell trait (ECAST) for further advice ${ }^{68}$ 
neurology) to consider that ERM can happen to anyone who is exposed to unaccustomed exercise. The threshold, however, is much lower in patients with an underlying genetic disorder. In addition, several other exogenous and endogenous factors also lower this threshold. The most important question is whether the level and type of exercise in combination with other exogenous and endogenous factors is sufficient to explain the rhabdomyolysis episode. If not, screening for an underlying genetic (neuromuscular) disorder needs to be performed.

Future research should focus on defining specific, evidence-based training and exercise advice for patients with various myopathies, in order to prevent recurrent episodes of rhabdomyolysis while enabling patients to optimise their physical condition or even improve their strength. New treatments to reduce the risk of ERM should be prospectively tested in various cohorts of patients with genetic risk factors for rhabdomyolysis. ${ }^{13}$

\section{Author affiliations}

${ }^{1}$ MRC Centre for Neuromuscular Diseases, Institute of Neurology, University College London, London, UK

${ }^{2} \mathrm{MH}$-investigation Unit, Department of Anesthesia, Canisius-Wilhelmina Hospital, Nijmegen, The Netherlands

${ }^{3}$ Departments of Anesthesia and of Biomedicine, Basel University Hospital, Basel, Switzerland

${ }^{4}$ Department of Life Sciences, General Pathology Section, University of Ferrara, Ferrara, Italy

${ }^{5}$ Institut de Myologie, Hôpital Pitié-Salpêtrière, Paris, France

${ }^{6}$ Department of Paediatric Neurology-Neuromuscular Service, Evelina Children's Hospital, Guy's \& St Thomas' NHS Foundation Trust, London, UK

${ }^{7}$ Randall Division of Cell and Molecular Biophysics, Muscle Signalling Section, London, UK

${ }^{8}$ Department of Basic and Clinical Neuroscience, Institute of Psychiatry, Psychology and Neuroscience (IoPPN), King's College London, London, UK ${ }^{9}$ Department of Neurology, Radboud University Medical Centre, Nijmegen, The Netherlands

Competing interests None declared.

Provenance and peer review Not commissioned; externally peer reviewed.

Open Access This is an Open Access article distributed in accordance with the Creative Commons Attribution Non Commercial (CC BY-NC 4.0) license, which permits others to distribute, remix, adapt, build upon this work noncommercially, and license their derivative works on different terms, provided the original work is properly cited and the use is non-commercial. See: http:// creativecommons.org/licenses/by-nc/4.0/

\section{REFERENCES}

1. Sinert R, Kohl L, Rainone T, et al. Exercise-induced rhabdomyolysis. Ann Emerg Med 1994;23:1301-6.

2. Melli G, Chaudhry V, Cornblath DR. Rhabdomyolysis: an evaluation of 475 hospitalized patients. Medicine 2005;84:377-85.

3. Dlamini N, Voermans NC, Lillis S, et al. Mutations in RYR1 are a common cause of exertional myalgia and rhabdomyolysis. Neuromuscul Disord 2013;23:540-8.

4. Furman J. When exercise causes exertional rhabdomyolysis. JAAPA 2015;28:38-43.

5. Goldberg J, Magruder KM, Forsberg CW, et al. Prevalence of post-traumatic stress disorder in aging Vietnam-era veterans: veterans administration cooperative study 569: course and consequences of post-traumatic stress disorder in Vietnam-era veteran twins. Am J Geriatr Psychiatry 2016;24:181-91.

6. Nance JR, Mammen AL. Diagnostic evaluation of rhabdomyolysis. Muscle Nerve 2015;51:793-810.
7. Barca E, Emmanuele V, DiMauro SB. Metabolic myoglobinuria. Curr Neurol Neurosci Rep 2015;15:69.

8. Landau ME, Kenney K, Deuster P, et al. Exertional rhabdomyolysis: a clinical review with a focus on genetic influences. J Clin Neuromuscul Dis 2012;13:122-36.

9. Quinlivan R, Jungbluth $\mathrm{H}$. Myopathic causes of exercise intolerance with rhabdomyolysis. Dev Med Child Neurol 2012;54:886-91.

10. Rebbeck RT, Willemse H, Groom L, et al. Regions of ryanodine receptors that influence activation by the dihydropyridine receptor 31 a subunit. Skelet Muscle 2015;5:23.

11. Ellis C, Cuthill J, Hew-Butler T, et al. Case report: exercise-associated hyponatremia with rhabdomyolysis during endurance exercise. Phys Sportsmed 2009;37:126-32.

12. Katsarou A, Singh S. Hyponatraemia associated rhabdomyolysis following water intoxication. BMJ Case Rep 2010;2010:pii: bcr0220102720.

13. Sanchis-Gomar F, Pareja-Galeano H, Perez-Quilis $\mathrm{C}$, et a/Effects of allopurinol on exercise-induced muscle damage: new therapeutic approaches? Cell Stress Chaperones 2015;20:3-13.

14. Hamel Y, Mamoune A, Mauvais FX, et al. Acute rhabdomyolysis and inflammation. J Inherit Metab Dis 2015;38:621-8.

15. Bosch X, Poch E, Grau JM. Rhabdomyolysis and acute kidney injury. N Engl J Med 2009;361:62-72.

16. Nurenberg P, Giddings CJ, Stray-Gundersen J, et al. MR imaging-guided muscle biopsy for correlation of increased signal intensity with ultrastructural change and delayed-onset muscle soreness after exercise. Radiology 1992;184:865-9.

17. Brown AS, Davis JM, Murphy EA, et al. Gender differences in viral infection after repeated exercise stress. Med Sci Sports Exerc 2004;36:1290-5.

18. O'Connor FG, Brennan FH Jr, Campbell W, et al. Return to physical activity after exertional rhabdomyolysis. Curr Sports Med Rep 2008;7:328-31.

19. Joy TR, Hegele RA. Narrative review: statin-related myopathy. Ann Intern Med 2009;150:858-68.

20. Kenney K, Landau ME, Gonzalez RS, et al. Serum creatine kinase after exercise: drawing the line between physiological response and exertional rhabdomyolysis. Muscle Nerve 2012;45:356-62.

21. Brewster LM, Stronks K, Zwinderman AH, et al. Creatine kinase and the correlates of blood pressure in a random population sample. Hypertension 2008;51:e4-5.

22. Neal RC, Ferdinand KC, Ycas J, et al. Relationship of ethnic origin, gender, and age to blood creatine kinase levels. Am J Med 2009;122:73-8.

23. Kyriakides T, Angelini C, Schaefer J, et al. EFNS guidelines on the diagnostic approach to pauci- or asymptomatic hyperCKemia. Eur J Neurol 2010;17:767-73.

24. Clarkson PM. Exertional rhabdomyolysis and acute renal failure in marathon runners. Sports Med 2007;37:361-3.

25. Alpers JP, Jones LK Jr. Natural history of exertional rhabdomyolysis: a population-based analysis. Muscle Nerve 2010;42:487-91.

26. Smoot MK, Amendola A, Cramer E, et al. A cluster of exertional rhabdomyolysis affecting a Division I Football team. Clin J Sport Med 2013;23:365-72.

27. Oh RC, Arter JL, Tiglao SM, et al. Exertional rhabdomyolysis: a case series of 30 hospitalized patients. Mil Med 2015;180: 201-7.

28. McMahon GM, Zeng X, Waikar SS. A risk prediction score for kidney failure or mortality in rhabdomyolysis. JAMA Intern Med 2013;173:1821-8.

29. Knapik JJ. Extreme conditioning programs: potential benefits and potential risks. J Spec Oper Med 2015;15:108-13.

30. Cleary MA, Sadowski KA, Lee SY, et al. Exertional rhabdomyolysis in an adolescent athlete during preseason conditioning: a perfect storm. J Strength Cond Res 2011;25:3506-13.

31. Eichner ER. An outbreak of muscle breakdown: a morality play in four acts. Curr Sports Med Rep 2010;9:325-6.

32. Eichner ER. Ramifications of rhabdomyolysis. Curr Sports Med Rep 2014;13:135-6.

33. Olerud JE, Homer LD, Carroll HW. Incidence of acute exertional rhabdomyolysis. Serum myoglobin and enzyme levels as indicators of muscle injury. Arch Intern Med 1976;136:692-7.

34. Chevion S, Moran DS, Heled Y, et al. Plasma antioxidant status and cell injury after severe physical exercise. Proc Natl Acad Sci USA 2003;100:5119-23.

35. Clarkson PM. Case report of exertional rhabdomyolysis in a 12-year-old boy. Med Sci Sports Exerc 2006;38:197-200.

36. Lin $\mathrm{H}, \mathrm{Chie} \mathrm{W}$, Lien $\mathrm{H}$. Epidemiological analysis of factors influencing an episode of exertional rhabdomyolysis in high school students. Am J Sports Med 2006;34:481-6. 
37. Brown JA, Elliott MJ, Sray WA. Exercise-induced upper extremity rhabdomyolysis and myoglobinuria in shipboard military personnel. Mil Med 1994;159:473-5.

38. Sayers SP, Clarkson PM, Rouzier PA, et al. Adverse events associated with eccentric exercise protocols: six case studies. Med Sci Sports Exerc 1999;31:1697-702.

39. Springer BL, Clarkson PM. Two cases of exertional rhabdomyolysis precipitated by personal trainers. Med Sci Sports Exerc 2003;35:1499-502.

40. Pearcey GE, Bradbury-Squires DJ, Power KE, et al. Exertional rhabdomyolysis in an acutely detrained athlete/exercise physiology professor. Clin J Sport Med 2013;23:496-8.

41. Eichner ER. Tough Mudder injuries, Triathlon Drownings, and Team Rhabdomyolysis in the Navy. Curr Sports Med Rep 2014;13:66-7.

42. Greenberg MR, Kim PH, Duprey RT, et al. Unique obstacle race injuries at an extreme sports event: a case series. Ann Emerg Med 2014;63:361-6.

43. Juray RM. Exertional rhabdomyolysis in unsupervised exercises in a correctional setting: a case study. Urol Nurs 2005;25:117-19.

44. Norquist C, LoVecchio F, Young MR. The card game: outcomes after exercise-induced rhabdomyolysis in prisoners. Am J Emerg Med 2009;27:115-16.

45. MacDonald R, Rosner Z, Venters H. Case series of exercise-induced rhabdomyolysis in the New York City jail system. Am J Emerg Med 2014;32:466-7.

46. Atias D, Druyan A, Heled Y. Recurrent exertional rhabdomyolysis: coincidence, syndrome, or acquired myopathy? Curr Sports Med Rep 2013;12:365-9.

47. Warren JD, Blumbergs PC, Thompson PD. Rhabdomyolysis: a review. Muscle Nerve 2002;25:332-47.

48. Scharman EJ, Troutman WG. Prevention of kidney injury following rhabdomyolysis: a systematic review. Ann Pharmacother 2013;47:90-105.

49. Mannix R, Tan ML, Wright R, et al. Acute pediatric rhabdomyolysis: causes and rates of renal failure. Pediatrics 2006;118:2119-25.

50. Snoeck M, van Engelen BG, Küsters B, et al. RYR1-related myopathies: a wide spectrum of phenotypes throughout life. Eur J Neurol 2015;22:1094-112.

51. Wappler F. Malignant hyperthermia. Eur J Anaesthesiol 2001;18:632-52.

52. Davis M, Brown R, Dickson A, et al. Malignant hyperthermia associated with exercise-induced rhabdomyolysis or congenital abnormalities and a novel RYR1 mutation in New Zealand and Australian pedigrees. Br J Anaesth 2002;88:508-15.

53. Vladutiu GD, Isackson PJ, Kaufman K, et al. Genetic risk for malignant hyperthermia in non-anesthesia-induced myopathies. Mol Genet Metab 2011;104:167-73.

54. Maffulli N, Margiotti K, Longo UG, et al. The genetics of sports injuries and athletic performance. Muscles Ligaments Tendons $\mathrm{J}$ 2013;3:173-89.

55. Papadimitriou ID, Lucia A, Pitsiladis YP, et al. ACTN3 R577X and ACE I/D gene variants influence performance in elite sprinters: a multi-cohort study. BMC Genomics 2016;17:285.

56. Garton FC, North KN. The effect of heterozygosity for the ACTN3 null allele on human muscle performance. Med Sci Sports Exerc 2016:48:509-20.

57. Quattrone RD, Eichner ER, Beutler A, et al. Exercise collapse associated with sickle cell trait (ECAST): case report and literature review. Curr Sports Med Rep 2015;14:110-16.

58. Seto JT, Lek M, Quinlan KG, et al. Deficiency of alpha-actinin-3 is associated with increased susceptibility to contraction-induced damage and skeletal muscle remodeling. Hum Mol Genet 2011;20:2914-27.

59. Lee FX, Houweling PJ, North KN, et al. How does alpha-actinin-3 deficiency alter muscle function? Mechanistic insights into
ACTN3, the 'gene for speed'. Biochim Biophys Acta 2016;1863:686-93.

60. Deuster PA, Contreras-Sesvold CL, O'Connor FG, et al. Genetic polymorphisms associated with exertional rhabdomyolysis. Eur J Appl Physiol 2013;113:1997-2004

61. Delaney KA, Givens ML, Vohra RB. Use of RIFLE criteria to predict the severity and prognosis of acute kidney injury in emergency department patients with rhabdomyolysis. J Emerg Med 2012;42:521-8.

62. Zutt R, van der Kooi AJ, Linthorst GE, et al. Rhabdomyolysis: review of the literature. Neuromuscul Disord 2014;24:651-9.

63. von Keudell AG, Weaver MJ, Appleton PT, et al. Diagnosis and treatment of acute extremity compartment syndrome. Lancet 2015;386:1299-310.

64. Lee E, Chahin N. A patient with mutation in the SCN4A p.M1592v presenting with fixed weakness, rhabdomyolysis, and episodic worsening of weakness. Muscle Nerve 2013;48:306-7.

65. Szczepanik ME, Heled Y, Capacchione J, et al. Exertional rhabdomyolysis: identification and evaluation of the athlete at risk for recurrence. Curr Sports Med Rep 2014;13:113-19.

66. Smith R, Jones N, Martin D, et al. 'Too much of a coincidence': identical twins with exertional heatstroke in the same race. BMJ Case Rep 2016;2016: pii:bcr2015212592.

67. Harrelson GL, Fincher AL, Robinson JB. Acute exertional rhabdomyolysis and its relationship to sickle cell trait. $J$ Athl Train 1995;30:309-12.

68. Asplund CA, O'Connor FG. Challenging return to play decisions: heat stroke, exertional rhabdomyolysis, and exertional collapse associated with sickle cell trait. Sports health. 2016:8:117-25.

69. Scalco RS, Gardiner AR, Pitceathly RD, et al. CAV3 mutations causing exercise intolerance, myalgia and rhabdomyolysis: expanding the phenotypic spectrum of caveolinopathies. Neuromuscul Disord 2016;26:504-10. Epub 2016 May 11.

70. Lindberg C, Sixt C, Oldfors A. Episodes of exercise-induced dark urine and myalgia in LGMD 2I. Acta Neurol Scand 2012;125:285-7.

71. Lahoria R, Milone M. Rhabdomyolysis featuring muscular dystrophies. J Neurol Sci 2016;361:29-33.

72. Yamin C, Amir O, Sagiv M, et al. ACE ID genotype affects blood creatine kinase response to eccentric exercise. J Appl Physiol (1985) 2007;103:2057-61.

73. Pimenta EM, Coelho DB, Cruz IR, et alThe ACTN3 genotype in soccer players in response to acute eccentric training. Eur J Appl Physiol 2012;112:1495-503.

74. Hubal MJ, Devaney JM, Hoffman EP, et al. CCL2 and CCR2 polymorphisms are associated with markers of exercise-induced skeletal muscle damage. J Appl Physiol (1985) 2010;108:1651-8.

75. Clarkson PM, Hoffman EP, Zambraski E, et al. ACTN3 and MLCK genotype associations with exertional muscle damage. J Appl Physiol (1985) 2005;99:564-9.

76. Heled Y, Bloom MS, Wu TJ, et al. CK-MM and ACE genotypes and physiological prediction of the creatine kinase response to exercise. $J$ Appl Physiol (1985) 2007;103:504-10.

77. Devaney JM, Hoffman EP, Gordish-Dressman H, et al. IGF-II gene region polymorphisms related to exertional muscle damage. J Appl Physiol (1985) 2007;102:1815-23.

78. Yamin C, Duarte JA, Oliveira JM, et al. IL6 (-174) and TNFA (-308) promoter polymorphisms are associated with systemic creatine kinase response to eccentric exercise. Eur J Appl Physiol 2008;104:579-86.

79. Wappler F, Fiege M, Steinfath M, et al. Evidence for susceptibility to malignant hyperthermia in patients with exercise-induced rhabdomyolysis. Anesthesiology 2001;94:95-100.

80. Giannoglou GD, Chatzizisis YS, Misirli G. The syndrome of rhabdomyolysis: pathophysiology and diagnosis. Eur J Intern Med 2007;18:90-100. 